\title{
Evaluation of the Role of Hexokinase Type II in Cellular Proliferation and Apoptosis Using Human Hepatocellular Carcinoma Cell Lines
}

\author{
Keun Jae Ahn ${ }^{1}$, Hee Sung Hwang ${ }^{2}$, Jeon Han Park ${ }^{3}$, Seong Hye Bang ${ }^{1}$, Won Jun Kang ${ }^{1}$, Mijin Yun ${ }^{1}$, and Jong Doo Lee ${ }^{1}$ \\ ${ }^{I}$ Division of Nuclear Medicine, Department of Radiology, Research Institute of Radiological Science, Yonsei University College of \\ Medicine, Seoul, Korea; ${ }^{2}$ Division of Nuclear Medicine, Department of Radiology, Hallym University Sacred Heart Hospital, \\ Pyeongchon-dong, Dongan-gu, Anyang-si, Gyeonggi-do, Korea; and ${ }^{3}$ Department of Microbiology and Brain Korea 21 Project for \\ Medical Sciences, Institute for Immunology and Immunological Diseases, Yonsei University College of Medicine, Seoul, Korea
}

The ${ }^{18} \mathrm{~F}-\mathrm{FDG}$ uptake pattern on PET could be an indicator of the prognosis and aggressiveness of various tumors, including hepatocellular carcinoma (HCC). Hexokinase, especially hexokinase type II (HKII), plays a critical role in ${ }^{18} \mathrm{~F}-\mathrm{FDG}$ uptake in rapidly growing tumors. We established a stable cell line overexpressing HKII by the transfection of full DNA of HKII to HCC cells (SNU449) that express low levels of HKII and investigated how ${ }^{18} \mathrm{~F}-\mathrm{FDG}$ uptake mechanisms, especially overexpression of HKII, are linked to tumor proliferation mechanisms. Methods: The HKII gene was stably transfected to SNU449 cells with an expression vector. HKII expression in the cells was verified by reverse-transcriptase polymerase chain reaction, Western blot analysis, adenosine triphosphate (ATP) and lactate production, ${ }^{18} \mathrm{~F}-\mathrm{FDG}$ uptake measurement, and confocal microscopy. Cellular proliferation activity and response to the anticancer drug cisplatin were evaluated by cell counting using 3-(4,5-dimethylthiazol-2-yl)-2,5-diphenyltetrazolium bromide assay. For the evaluation of molecular pathways involved in tumor proliferation, the phosphatidylinositol 3-kinase (PI3K)/Akt pathway was investigated. Results: The stable cell line produced HKII effectively, but expression of other enzymes or transporters for glycolysis, such as glucose-6-phosphatase (G6Pase), HKI and III, and glucose transporter type 1 and 2 (Glut-1 and Glut-2), did not show any changes. ${ }^{18} \mathrm{~F}-\mathrm{FDG}$ uptake was significantly increased after transfection. ATP and lactate production was also increased after transfection. Overexpressed HKII was associated with mitochondria on confocal microscopy. Cells with overexpression of HKII, compared with the nontransfected cell line, showed 1.5to 2-fold higher cell survival and resistance to the anticancer agent cisplatin (2- to 8-fold). In the molecular study, the activated form of Akt was increased after transfection, and PI3K inhibitor dissociated the mitochondrial HKII to the cytoplasm. In addition, the adenosine monophosphate-activated protein kinase (AMPK) pathway is also involved in Akt signaling. Conclusion: HKII plays an important role in ${ }^{18} \mathrm{~F}-\mathrm{FDG}$ uptake and tumor proliferation by both the PI3K-dependent and the PI3K-independent Akt signal pathways; therefore, the ${ }^{18} \mathrm{~F}-\mathrm{FDG}$ uptake pattern on a PET scan can be a surrogate marker of prognosis in HCC.

Received Dec. 1, 2008; revision accepted May 27, 2009.

For correspondence or reprints contact: Jong Doo Lee, Division of Nuclear Medicine, Department of Diagnostic Radiology, Yonsei University College of Medicine, 250 Seongsan-ro, Seodaemun-gu, Seoul, 120-752, Korea.

E-mail: jdlee@yuhs.ac

COPYRIGHT ( 2009 by the Society of Nuclear Medicine, Inc.
Key Words: hepatocellular carcinoma; hexokinase; ${ }^{18} \mathrm{~F}-\mathrm{FDG}$ uptake; PI3K/Akt signaling; prognosis

J Nucl Med 2009; 50:1525-1532

DOI: 10.2967/jnumed.108.060780

B ecause of its high sensitivity and specificity in the diagnosis and staging of various cancers or detection of recurrent tumors after treatment, ${ }^{18} \mathrm{~F}-\mathrm{FDG}$ PET is widely used in the oncology field (1). As cancer cell growth depends on glucose metabolism as a major energy substrate, increased ${ }^{18} \mathrm{~F}-\mathrm{FDG}$ uptake on PET scans is known to be an indicator of the poor prognosis and aggressiveness of various tumors $(2,3)$. The main mechanisms of ${ }^{18} \mathrm{~F}-\mathrm{FDG}$ uptake in tumor cells are increased expression of the facilitated glucose transporters including type 1 (Glut-1) on the cell membrane and rate-limiting glycolytic enzymes, especially hexokinase type II (HKII) (4). It has been reported that well-differentiated hepatocellular carcinoma (HCC) shows low ${ }^{18}$ F-FDG uptake, but poorly differentiated HCC shows increased HKII expression and, subsequently, increased ${ }^{18} \mathrm{~F}-\mathrm{FDG}$ uptake (5).

In the early 1930s, Dr. Otto Warburg reported that tumor cells have high glycolytic rates despite high oxygen concentration, which is known as the Warburg effect (6). Tumor cells use more glucose than normal cells through insufficient energy metabolism by producing lactate instead of using oxidative phosphorylation $(7,8)$. As tumor cells with uncontrolled cell growth need more energy, the essential enzyme hexokinase is overexpressed to maintain high glycolytic activity $(9,10)$. In particular, most malignant cells express HKII instead of HKI (7), especially the mitochondrially bound form (11). Mitochondria-bound hexokinases have the advantage of using adenosine triphosphate (ATP) produced by oxidative phosphorylation in the mitochondria as the substrate to phosphorylate incoming glucose $(12,13)$. Furthermore, hexokinase binds to the outer mitochondrial membrane at sites where the voltage-depen- 
dent anion channel (VDAC) is located (14). The VDACs are in close association with the adenine nucleotide translocator (ANT), which facilitates the exchange of cytoplasmic adenosine diphosphate for mitochondrial ATP (15).

Recently, it has been reported that the VDAC-ANT complex plays an important role in regulating mitochondrial permeability transition and release of apoptotic factors such as cytochrome c $(15,16)$. V-akt murine thymoma viral oncogene (Akt), known as a protein kinase $\mathrm{B}$, mediates translocation of cytosolic HKII to the mitochondrial outer membrane for producing a VDAC-ANT-HKII complex that prevents cytochrome c release and apoptosis. From the clinical aspect, poorly differentiated HCC expresses HKII much higher than low-grade HCC, although Glut-1 expression is not always increased $(5,17,18)$. Those poorly differentiated HCCs show high uptake of ${ }^{18} \mathrm{~F}-\mathrm{FDG}$ on the ${ }^{18} \mathrm{~F}-\mathrm{FDG}$ PET scan and poor survival $(2,3)$. Therefore, HKII appears to play an important role in maintaining malignancy in tumor cells with poor survival, but molecular mechanisms, especially the relationship between ${ }^{18} \mathrm{~F}-\mathrm{FDG}$ uptake mechanisms with regard to tumor progression, have not yet been well investigated.

In this study, we transfected full-length DNA of HKII into the SNU449 human HCC cell line that shows low HKII expression and investigated the role of HKII in ${ }^{18} \mathrm{~F}-\mathrm{FDG}$ uptake with regard to the molecular mechanisms of the cellular proliferation, antiapoptotic effect, and chemotherapeutic response. This experimental study could provide biologic evidence of increased ${ }^{18} \mathrm{~F}-\mathrm{FDG}$ uptake on the PET scan as a surrogate marker of poor prognosis in HCC.

\section{MATERIALS AND METHODS}

\section{Materials}

DEAE-Sepharose Fast Flow, CM-Sepharose Fast Flow, and Sephacryl S-200 High Resolution were purchased from Amersham Biosciences, and Ni-NTA resin, $\beta$-D-thiogalactopyranoside (IPTG), cisplatin, 4-(2-hydroxyethyl)-1-piperazineethane sulfanic acid (HEPES) buffer, and dithioerythritol were purchased from Sigma. Leupeptin, pepstatin, phenylmethanesulphonylfluoride (PMSF), and imidazole were purchased from Boehringer Manheim. Glucose, Leuconostoc mesentroides glucose-6-phosphate dehydrogenase (G6PD), and ATP (disodium salt) were obtained from Roche Chemical Co. Nicotinamide adenine dinucleotide $\left(\mathrm{NAD}^{+}\right.$, disodium salt) was purchased from Fluka Chemical Co.

\section{Cell Culture and Gene Expression Profile of HKII}

SNU449 and SNU-475 human HCC cell lines were obtained from the Korean Cell Line Bank and grown in RPMI 1640 supplemented with $10 \%$ heat-inactivated fetal bovine serum, penicillin $(100 \mathrm{U} / \mathrm{mL})$, and streptomycin $(100 \mu \mathrm{g} / \mathrm{mL})$. Control hepatocytes (Chang cells), HepG2, and Hep3B human HCC cell lines obtained from the American Type Culture Collection were maintained in Dulbecco's modified Eagle's medium supplemented with $10 \%$ fetal bovine serum and penicillin-streptomycin (100 $\mathrm{U} / \mathrm{mL}$ ) in a humidified atmosphere of $95 \%$ air and $5 \% \mathrm{CO}_{2}$ at $37^{\circ} \mathrm{C}$. We evaluated HKII expression in those cell lines. As shown in Supplemental Figure 1, HepG2 or Hep3B and SNU-475 cells showed high expression of HKII, whereas SNU449 cells showed significantly lower expression, compared with other cell lines.

\section{Construction of Expression Vectors for HKII}

The protein coding regions of the full-length of HKII were amplified by polymerase chain reaction (PCR) with a 5 '-oligonucleotide primer CGAGCTCCATATGA TTGCCTCGCATCTGCT and the $3^{\prime}$-oligonucleotide primers CGGAATTCTTAATGA TGATGATGATGTCGCTGTCCAGCCT containing the restriction enzyme sites underlined above, respectively. The amplified DNAs were gel-purified, digested with appropriate enzymes, and then ligated into the pRSET A bacterial expression vector (Invitrogen) that had been digested with the appropriate restriction enzymes. All constructs were confirmed by DNA sequencing. To generate mammalian expression plasmid DNA, the HKII construct was isolated from pRSET A by a Nde I/Klenow and EcoR I treatment and then ligated into pcDNA 3.1/Myc-His (Invitrogen) treated with $E c o R$ V and $E c o R$ I. The construct was confirmed by DNA sequencing.

\section{Bacterial Expression and Purification of Recombinant HKII Proteins}

The rhHKII was overexpressed in Escherichia coli (BL21), and the recombinant proteins were purified to apparent homogeneity. The proteins were purified by Ni-NTA resin according to the manufacturer's instruction (Sigma). The proteins were concentrated and buffer-changed with a Centricon apparatus (Amicon). The proteins were measured with the bicinchoninic acid (BCA) assay and stored at $-70^{\circ} \mathrm{C}$.

\section{Establishment of Stable Cell Lines Expressing HKII in HCC Cells}

To investigate whether HKII overexpression induces rapid cell growth, proliferation, and antiapoptotic effect in tumor cells, we transfected HKII into the HCC cell line SNU449 (low expression of HKII) and Chang cells (normal hepatic cell line). To obtain stable HKII-expressing cell lines, we plated SNU449 and Chang cells at a density of 150,000 cells/60-mm dish $20 \mathrm{~h}$ before transfection. For transfection, lipofectamine $(15 \mu \mathrm{L})$ with $4 \mu \mathrm{g}$ of plasmid DNA was added, and the cells were incubated at $37^{\circ} \mathrm{C}$ for $4 \mathrm{~h}$ and washed once with serum-free RPMI 1640. After 14-20 $\mathrm{d}$ of selection in medium containing $1 \mathrm{mg}$ of Geneticin (G418; Invitrogen) per milliliter, resistant colonies were isolated with cloning rings and transferred to separate culture dishes for expansion. After transfection of the HKII gene, in the case of SNU449-HKII cells the RNA level was much higher than that in nontransfected SNU449 cells and was similar to that of HepG2 HKII, which was a positive control. Additionally, after transfection of HKII into Chang cells, we could confirm the elevation of HKII level in Chang cells. These results showed similar patterns in protein level (Fig. 1).

\section{${ }^{18}$ F-FDG Uptake Study}

For radiotracer uptake measurement, $5 \times 10^{4}$ cells were seeded in a cavity of a 24-well plate (Greiner) and cultured in a humidified atmosphere of $5 \% \mathrm{CO}_{2}$ at $37^{\circ} \mathrm{C}$ using the abovementioned cell culture medium. ${ }^{18} \mathrm{~F}$-FDG uptake was determined on confluent cells by incubation of the cells for $30 \mathrm{~min}$ at $37^{\circ} \mathrm{C}$ with fresh medium containing $185 \mathrm{kBq}(5 \mu \mathrm{Ci})$ of ${ }^{18} \mathrm{~F}-\mathrm{FDG} / \mathrm{mL}$. Cells were washed 5 times with $5 \mathrm{~mL}$ of ice-cold phosphate- 


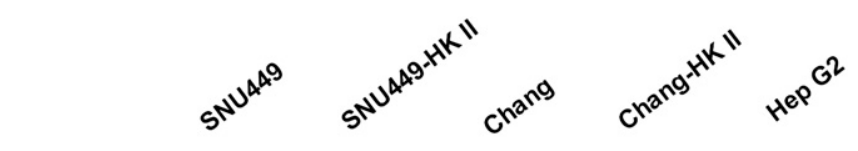

HK II

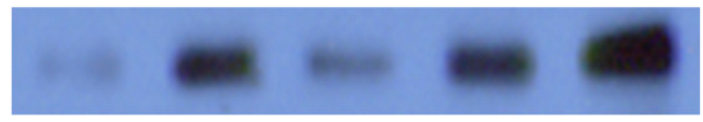

Actin

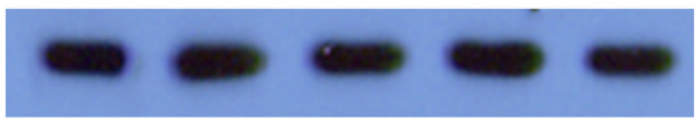

FIGURE 1. Expression profile of HKII in established stable cells. Expression of HKII is significantly increased after transfection in both SNU449 human HCC cell line and control Chang cells. HepG2 cell line was used as positive control for HKII. $\beta$-actin was used as loading controls for Western blot analysis. SNU449-HKII = stable cells after transfection of HKII; Chang-HKII = stable cells after transfection of HKII.

buffered saline (PBS). Images were obtained on a PET scanner (Allegro; Philips-ADAC Medical Systems). An emission scan of 3 min was taken on the 12-well plates. A transmission scan (4s) was immediately obtained using low-dose CT to correct for attenuation correction. The images were reconstructed using a row-action maximal likelihood algorithm for the Allegro system. Subsequently, cells were washed 5 times with ice-cold PBS and lysed in $0.5 \mathrm{~mL}$ of $0.1 \mathrm{M}$ sodium hydroxide with $1 \%$ sodium dodecyl sulfate (SDS). Cell lysates were counted with a Cobra II $\gamma$-counter (Canberra-Packard). Protein levels were quantified using the BCA protein assay kit (Pierce) according to the manufacturer's recommendations and bovine serum albumin (BSA) as protein standard.

\section{Immunofluorescence Assay of HKII Using Confocal Microscopy}

For confocal microscopic analysis, cells were seeded at $5 \times 10^{4}$ cells in a Laboratory-Tek German borosilicate cover glass with 8 chambers (Nunc; Nagel Inc.) and grown for $24 \mathrm{~h}$ in complete medium. Subsequently, cells were washed and preincubated in $200 \mu \mathrm{L}$ of RPMI. After incubation at $37^{\circ} \mathrm{C}$ for $30 \mathrm{~min}$, cells were fixed with $2 \%$ glutaraldehyde and $2 \%$ formaldehyde in PBS for 15 $\mathrm{min}$ at $37^{\circ} \mathrm{C}$. Cells then were washed with PBS containing $10 \mathrm{mM}$ ethylenediaminetetraacetic acid (EDTA), permeabilized with methanol for $10 \mathrm{~min}$ at $-20^{\circ} \mathrm{C}$, and washed 3 times with PBS containing $10 \mathrm{mM}$ EDTA. Cells were blocked for $1 \mathrm{~h}$ with PBS containing 5\% BSA. After that, cells were incubated with the primary antibody (anti-HKII, 1:250 dilution) at $4^{\circ} \mathrm{C}$ overnight, rinsed 3 times with PBS, blocked again for 15 min with PBS containing 5\% BSA, incubated with the secondary antibody (Alexa 594 goat-antimouse, 1:2,000 dilution) at room temperature for $2 \mathrm{~h}$, and then rinsed 3 times with PBS. Subsequently Mito Tracker Green FM (Molecular Probes) staining was performed as follows: Cells were washed once with PBS and then 0.1 M Tris/ $\mathrm{NaCl}$ buffer, $\mathrm{pH} 8.0$, containing $0.05 \% \mathrm{BSA}$ and were incubated with $100 \mathrm{nM}$ Mito Tracker Green FM for $15 \mathrm{~min}$ at $37^{\circ} \mathrm{C}$ in the dark in an atmosphere of $5 \% \mathrm{CO}_{2}$. Cells were further washed and placed in ice-cold PBS. Photographs were taken with a Zeiss model LSM510 invert on the base of an Axiovert 100 microscope (Carl Zeiss B.V.).
Total RNA Preparation and Reverse-Transcriptase

Polymerase Chain Reaction (RT-PCR)

An RNeasy kit (Qiagen) was used to extract total RNA from each sample of $2 \times 10^{6}$ cells. The Superscript II RT-PCR kit (Invitrogen) was used to generate cDNA from the total RNA isolated from each of the cell lines. The final cDNA of Glut-1-3, HKI-III, G6Pase, and glyceraldehyde-3-phosphate dehydrogenase was then determined with a spectrophotometer. PCR was performed for 35 cycles $\left(94^{\circ} \mathrm{C}\right.$ for $40 \mathrm{~s}, 55^{\circ} \mathrm{C}$ for $40 \mathrm{~s}$, and $72^{\circ} \mathrm{C}$ for $60 \mathrm{~s}$ per cycle) in a reaction mixture consisting of $5 \mathrm{~mL}$ of $10 \times$ PCR buffer (100 mM Tris-HCl, pH 8.8, $500 \mathrm{mM} \mathrm{KCl,} 15 \mathrm{mM}$ $\mathrm{MgCl}_{2}, 30 \mathrm{mM}$ dithiothreitol, $\left.1 \mathrm{mg} \mathrm{mL}{ }^{-1} \mathrm{BSA}\right), 1 \mathrm{~mL}$ of $10 \mathrm{mM}$ dNTPs, $1 \mathrm{~mL}$ of each primer $(10 \mathrm{mM}), 0.5 \mathrm{~mL}$ of Taq DNA polymerase (Roche), $500 \mathrm{ng}$ of cDNA template, and deionized distilled $\mathrm{H}_{2} \mathrm{O}\left(\mathrm{ddH}_{2} \mathrm{O}\right)$ to a total volume of $50 \mathrm{~mL}$. All PCR products were analyzed by electrophoresis on $1.5 \%$ agarose gels.

\section{Western Blot Analysis and Generation of Monoclonal Antibody Against HKII}

Cells were lysed using the following lysis buffer: $50 \mathrm{mM}$ Tris (pH 8.0), $110 \mathrm{mM} \mathrm{NaCl}, 5 \mathrm{mM}$ EDTA, 1\% Triton X-100, PMSF (100 $\mu \mathrm{g} / \mathrm{mL}$ ), $10 \%$ glycerol, $1.5 \mathrm{mM} \mathrm{MgCl}$, and protease inhibitor cocktail (Roche). Protein concentrations were determined using the BCA assay (Pierce). Whole-cell lysates containing 40$80 \mu \mathrm{g}$ of protein were boiled in equal volumes of loading buffer (125 mM Tris-Cl, pH 6.8, 4\% SDS, 20\% glycerol, and 10\% 2$\beta$-mercaptoethanol). Proteins were separated electrophoretically on $7.5 \%-10 \%$ denaturing polyacrylamide gels and subsequently transferred to Hybond enhanced chemiluminescence (ECL) nitrocellulose membranes (Amersham) using the BioRad Mini-Gel system. For immunoblotting, membranes were blocked with $5 \%$ nonfat dried milk in Tris-buffered saline (TBS) for $1 \mathrm{~h}$. The primary antibody, HKII (Chemicon), and our own generated antibody were applied at a 1:1,000 dilution for $1 \mathrm{~h}$. And each specific primary antibody was applied at 1:2,000-1:5,000 dilution for $1 \mathrm{~h}$. After washing twice with TBS containing $0.05 \%$ polysorbate 20 (TTBS), secondary antibody (peroxidase-conjugated; Zymed) was applied at a 1:5,000-1: 10,000 dilution for $1 \mathrm{~h}$. Blots were washed twice in TTBS for $10 \mathrm{~min}$, incubated in commercial ECL reagents (Pierce), and exposed to photographic film.

Because monoclonal antibody against human HKII is not commercially available, we generated an anti-HKII antibody that was produced from a mouse monoclonal antibody in our laboratory. Purified rhHKII protein was used to immunize BALB/c mice, and hybridomas were generated and cloned as previously described (19). A polyclonal antibody against HKI, Akt, p-Akt, PI3K, and phosphorylated adenosine monophosphate-activated protein kinase (p-AMPK) were purchased from Cell Signaling Technology. Antibodies against HKIII, Glut-1, Glut-2, and G-6Pase were purchased from Santa Cruz Biotechnology. All appropriate secondary antibodies (conjugated to horseradish peroxidase) were purchased from Zymed.

\section{Cell Growth and Viability in SNU449 Cell Lines Before and After Cisplatin Treatment}

Cell growth in vitro was determined using cell growth curve and 3-(4,5-dimethylthiazol-2-yl)-2,5-diphenyltetrazolium bromide (MTT) assay. For cell growth curve, cells were harvested by trypsinization, and the number of cells was counted. The effect of cisplatin on the viability of cells was determined by MTT assay. Cells were plated at $1 \times 10^{4}$ cells per well in $200 \mu \mathrm{L}$ of RPMI 
1640 complete medium containing various concentrations of cisplatin in a 96-well microtiter plate. A $10-\mu \mathrm{g}$ concentration of cisplatin was repeated in 10 wells. After incubation for $24-72 \mathrm{~h}$ at $37^{\circ} \mathrm{C}$ in a humidified incubator, cell viability was determined using the MTT assay. Briefly, $4 \mu \mathrm{L}$ of MTT reagent $(5 \mathrm{mg} / \mathrm{mL}$ in PBS) was added to each well and incubated for $2 \mathrm{~h}$, and the plate was centrifuged at $1,800 \mathrm{rpm}$ for $5 \mathrm{~min}$ at $4^{\circ} \mathrm{C}$. The MTT solution was removed from the wells by aspiration. Formazan crystals were dissolved in $150 \mu \mathrm{L}$ of dimethyl sulfoxide, and absorbance was recorded on a microplate reader at a 540-nm wavelength.

\section{Determination of Cellular ATP Content and Lactate Production in SNU449 Cell Lines Before and After Transfection}

ATP was determined using the CellTiter-Glo luminescent cell viability assay (Promega) based on ATP bioluminescence as a marker of cell viability. The luminescence produced by the luciferase-catalyzed luciferin plus ATP reaction was detected using a MicroLumat LB96P multiwell scanning spectrophotometer (EG\&G Berthold; Bad). The data were normalized to the control group.

Lactate was determined using a lactate assay kit (BioVision) and following the manufacturer's instructions. The absorbance was recorded on a microplate reader at a $570-\mathrm{nm}$ wavelength. The data were normalized to the control group.

\section{Evaluation of HKII in Cytosol and Mitochondria-Enriched} Fractions Before and After Treatment with PI3K Inhibitor

Cells were plated in $25-\mathrm{cm}^{2}$ flasks and used at a final density of $1.5 \times 10^{6}$ cells per flask. After $24 \mathrm{~h}$, cells were treated with LY294002 $(50 \mu \mathrm{M})$ for $1 \mathrm{~h}$ at $37^{\circ} \mathrm{C}$. After treatment, cells were harvested by trypsinization and centrifuged at $600 \mathrm{~g}$ for $10 \mathrm{~min}$ at $4^{\circ} \mathrm{C}$. The cell pellets were washed once in PBS and then resuspended in 3 volumes of isolation buffer $(20 \mathrm{mM}$ HEPES, $\mathrm{pH} 7.4,10 \mathrm{mM} \mathrm{KCl}, 1.5 \mathrm{mM} \mathrm{MgCl} 2,1 \mathrm{mM}$ sodium EDTA, $1 \mathrm{mM}$ dithiothreitol, $10 \mathrm{mM}$ phenylmethylsulfonyl fluoride, $10 \mu \mathrm{M}$ leupeptin, and $10 \mu \mathrm{M}$ aprotinin) in $250 \mathrm{mM}$ sucrose. After chilling on ice for $3 \mathrm{~min}$, cells were disrupted by 60 strokes of a glass homogenizer. The homogenate was centrifuged twice at $1,500 \mathrm{~g}$ at $4^{\circ} \mathrm{C}$ to remove unbroken cells and nuclei. The mito-

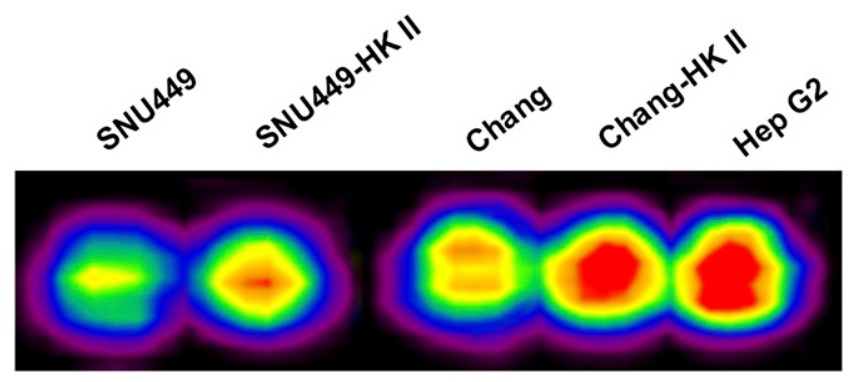

FIGURE 2. Measurement of ${ }^{18} \mathrm{~F}-\mathrm{FDG}$ uptake levels in established stable cells. ${ }^{18} \mathrm{~F}-\mathrm{FDG}$ PET images after transfection of HKII show significantly increased ${ }^{18} \mathrm{~F}-\mathrm{FDG}$ uptake in both SNU449 and Chang cells by approximately $52 \%$ and $40 \%$, respectively.

chondria-enriched fraction (heavy membrane fraction) was then collected by centrifugation at $12,000 \mathrm{~g}$ for $30 \mathrm{~min}$. The supernatant was removed and filtered through 0.2 - and then $0.1-\mu \mathrm{m}$ Ultrafree MC filters (Millipore) to give cytosolic protein.

\section{RESULTS}

\section{Expression Profiles of Hexokinase Isozymes, GLUTs,} and VDAC After HKII Transfection

We investigated whether HKII overexpression affects the expression of other glycolytic enzymes such as HKI, HKIII, and G6Pase and facilitated Glut-1 and Glut-2.

There was no significant alteration of gene expression of these enzymes or transporters. Expression of VDAC, which is important for mitochondrial association of hexokinases, was also not changed (Supplemental Fig. 2). ${ }^{18} \mathrm{~F}-\mathrm{FDG}$ uptake was significantly increased after transfection in both SNU449 and control Chang cells, approximately 52\% and 40\%, respectively (Fig. 2; Supplemental Fig. 3). On confocal microscopy, transfected cells, compared with nontransfected cells, show significantly increased HKII protein in the cells, and a large proportion of the HKII protein was mitochondrially associated (Fig. 3).

FIGURE 3. Subcellular localization of HKII in SNU449 and SNU449-HKII cells. Confocal microscopy shows markedly increased HKII expression after transfection (SNU449-HKII), and large proportion of HKIls are mitochondrially associated. (A-C) SNU449 cells. (D-F) SNU449 cells after transfection of HKII. HKII protein is shown in A and D (red); mitochondria are shown in $B$ and $E$ (green); and HKII colocalized with mitochondria is shown in $\mathrm{C}$ and $\mathrm{F}$ (yelloworange).
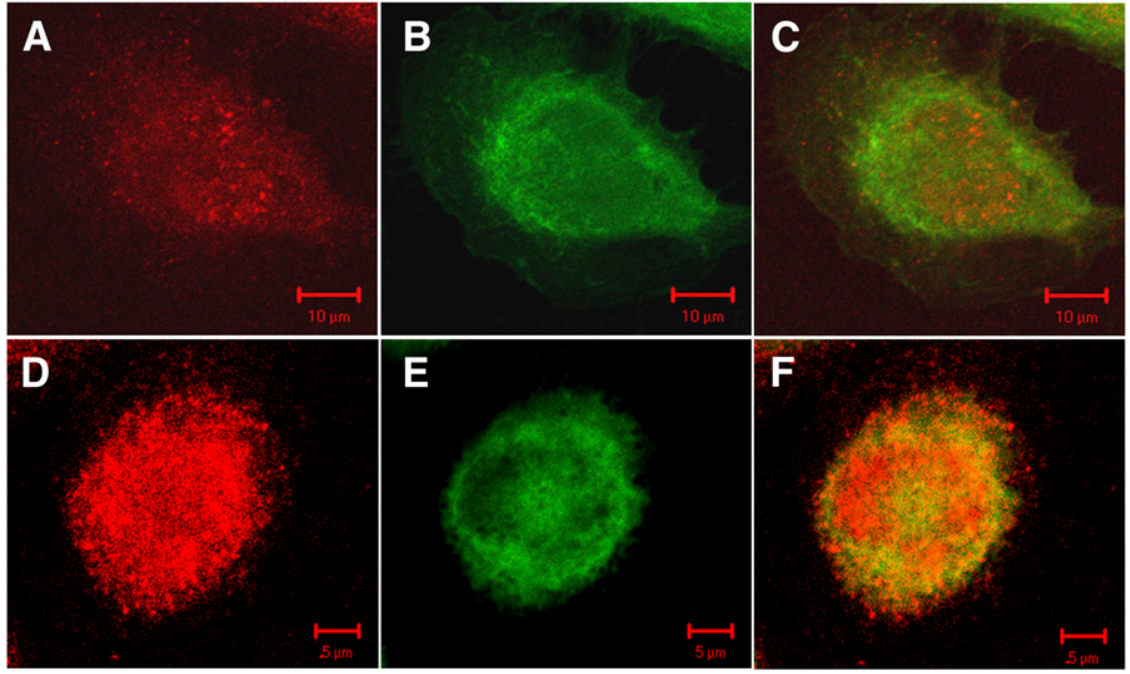

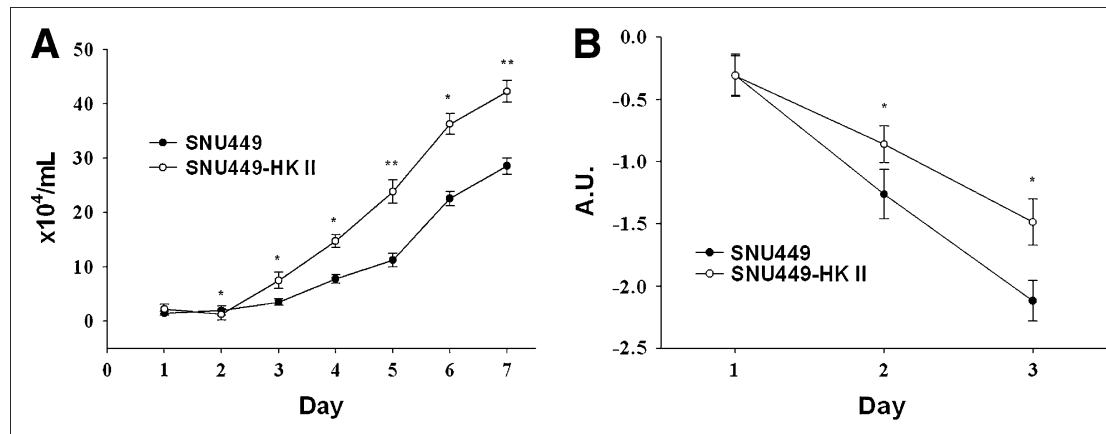

FIGURE 4. Effects of overexpressed HKII on cell growth and anticancer treatment response. Cellular proliferation is significantly increased after HKII transfection, approximately 1.5 - to 2-fold, compared with nontransfected cells (A). After treatment with cisplatin $(10 \mu \mathrm{g} / \mathrm{mL})$ for $3 \mathrm{~d}$ at $37^{\circ} \mathrm{C}$, there was 2 - and 8 -fold increase in cell survival 2 and $3 \mathrm{~d}$ after treatment, respectively (B). All measurements were performed in triplicate; error bars indicate SEM. Comparisons were subjected to Student $t$ test. A.U. = arbitrary unit. ${ }^{\star} P<0.05$. ${ }^{\star \star} P<0.01$.

\section{Cell Growth and Survival After Overexpression of HKII}

HKII-transfected SNU449 cells showed a higher proliferation rate, approximately 1.5- to 2- fold higher, than nontransfected SNU449 cells (Fig. 4A). In control Chang cells, there was no significant cellular proliferation after transfection (data not shown).

When we treated the cell lines with the anticancer agent cisplatin, HKII-transfected SNU449 cells showed poorer response than did the control nontransfected SNU449 cells. The data showed no change on day 1, but on days 2 and 3 there was a 2- and 8-fold higher cell survival after cisplatin treatment, respectively, in HKII-transfected SNU449 cells (Fig. 4B).

\section{Molecular Mechanisms of Overexpressed HKII Related to Cellular Proliferation and Resistance to Anticancer Agent}

HKII-transfected SNU449 cells, compared with nontransfected cells, showed increased ATP (20\%) and lactate (45\%) production but decreased phosphorylated AMPK (Fig. 5; Supplemental Fig. 4). Because activated Akt is known to play an important role in translocation of cytoplasmic hexokinases to the mitochondrial outer membrane (20), we measured Akt after transfection. Total amount of Akt was not different between transfected and nontrans-

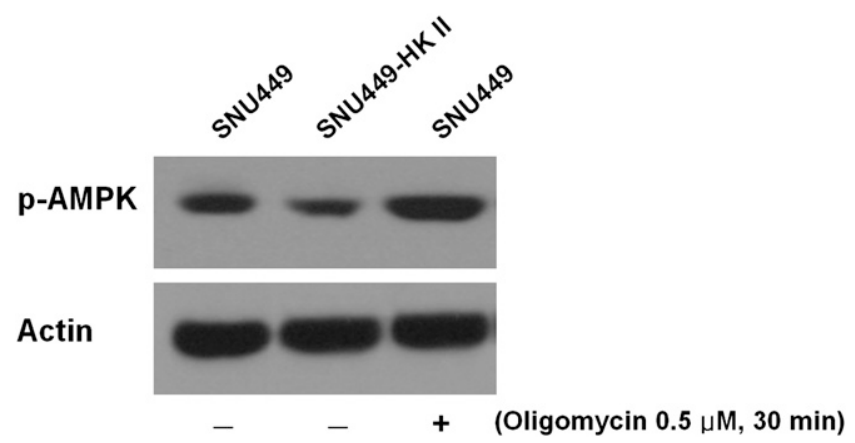

FIGURE 5. Effects of overexpressed HKII on AMPK phosphorylation. Activated form of AMPK (p-AMPK) is significantly decreased after HK II transfection (SNU449-HKII). Oligomycin $(0.5 \mu \mathrm{M}, 30 \mathrm{~min})$ served as positive control of p-AMPK because it is AMPK activator. fected SNU449 cells; however, the activated form (phosphorylated Akt, p-Akt) was significantly increased after transfection. Treatment of PI3K inhibitor LY294002 (50 $\mu \mathrm{M}$ ) induced reduction of p-Akt level (Fig. 6). In addition, mitochondrial HKII fraction was decreased, but cytoplasmic HKII was increased (Fig. 7). Therefore, our results suggest that the Akt signaling pathway is an important regulating mechanism for tumor progression and poor response to anticancer treatment; it is dependent on both the PI3K and the AMPK pathways because increased energy production (ATP) by overexpressed HKII could activate Akt alternatively by means of AMPK inactivation.

\section{DISCUSSION}

Several previous studies using ${ }^{18} \mathrm{~F}-\mathrm{FDG}$ PET have demonstrated that tumors with high ${ }^{18} \mathrm{~F}$-FDG uptake, compared with low-uptake tumors, including $\mathrm{HCC}$, have poor prog-

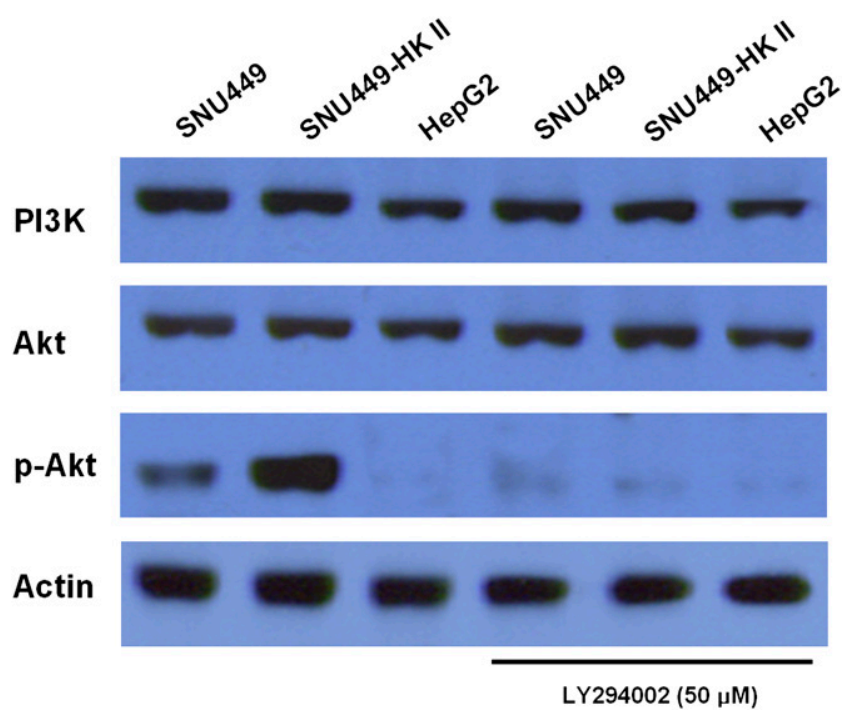

FIGURE 6. Effects of PI3K inhibitor treatment. Activated form of Akt ( $p$-Akt) was significantly increased after HKII transfection (SNU449-HKII), compared with control cells without transfection (SNU449). After treatment with $50 \mu \mathrm{M}$ PI3K inhibitor LY294002 for $1 \mathrm{~h}$, p-Akt level significantly decreased. $\beta$-actin served as loading control. 
FIGURE 7. Translocation of HK II from mitochondria to cytoplasm after treatment with PI3K inhibitor. Total amount of HKII protein was not changed after treatment with $50 \mu \mathrm{M} \mathrm{PI3K}$ inhibitor LY294002 for $1 \mathrm{~h}(\mathrm{~A})$. HKII is expressed more in mitochondrial fraction before treatment. After treatment with PI3K inhibitor, mitochondrial fraction decreased whereas cytosolic fraction increased (B). $\beta$-actin and Hsp 60 served as loading controls. Cyt $=$ cytoplasmic fraction $\mathrm{X} ; \mathrm{Mt}=$ mitochondria.
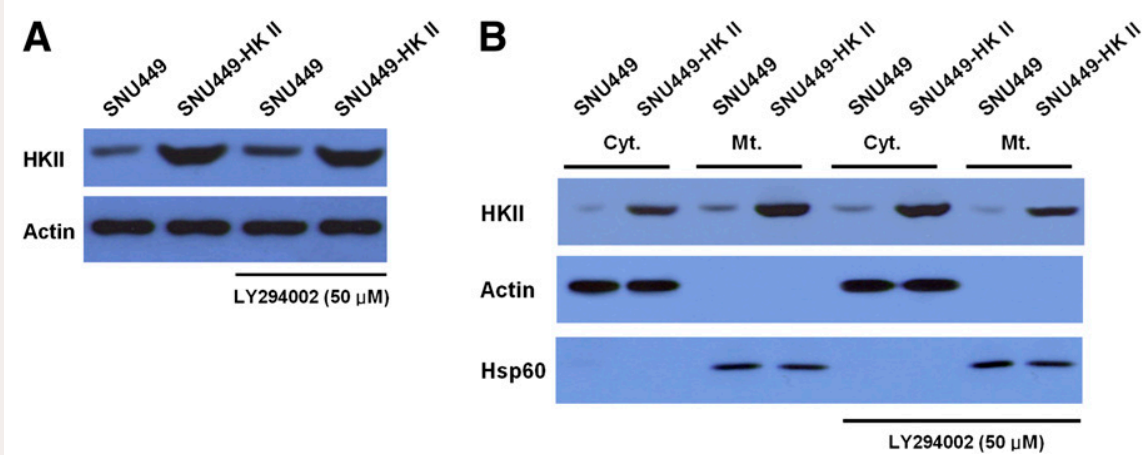

nosis $(21,22)$. As ${ }^{18} \mathrm{~F}$-FDG uptake in the tumor cells is mostly dependent on membrane-bound Glut and hexokinase expression levels $(4,23)$ and ${ }^{18} \mathrm{~F}-\mathrm{FDG}-6$-phosphate does not undergo further glycolytic pathways (24), either Glut or hexokinase expression might be related to tumor progression on the premise that ${ }^{18} \mathrm{~F}$-FDG uptake is correlated with tumor aggressiveness. However, ${ }^{18}$ F-FDG uptake appears to be more correlated with phosphorylating activity of the mitochondria-bound hexokinases rather than Glut-1 (25). In fact, high-grade HCCs showed low incidence of Glut-1 but increased HKII expression $(5,17,18)$. Therefore, hexokinase expression might play an important role in both ${ }^{18} \mathrm{~F}-\mathrm{FDG}$ uptake and tumor progression in HCC.

Most malignant cells express hexokinase, mostly HKII, up to 100 times higher than normal cells (26), and $50 \%-80 \%$ of HKIIs are bound to the outer membrane of mitochondria (7). Previous studies have demonstrated that hexokinases bound to the outer membrane of mitochondria produce an antiapoptotic activity $(16,27)$, which is strongly correlated with proliferation activity of malignant tumors (7). Therefore, we evaluated whether overexpressed HKII increases ${ }^{18} \mathrm{~F}-\mathrm{FDG}$ uptake and how it may affect cellular growth and proliferation. HKII overexpression was induced in the SNU449 cell line that expressed low levels of HKII. We confirmed through our established cell line that overexpression of HKII produced increased ${ }^{18} \mathrm{~F}$-FDG uptake and the HKII protein was mitochondrially associated on confocal microscopy; however, any other molecules that are related to gluconeogenesis and glycolysis were not changed (Supplemental Fig. 2). Thus, our cell line is an ideal model for the evaluation of the role of HKII as an increased ${ }^{18} \mathrm{~F}$-FDG uptake mechanism and tumor progression.

There are several mechanisms of hexokinase overexpression in malignant cells. In particular, it has been demonstrated that a short segment of the proximal region of HKII promotor contains functionally active response elements for c-Myc, hypoxia-inducible factor-1 (HIF-1), ras, and the tumor suppressor p53 with point mutations (28). These oncogenic alterations and related molecular pathways in malignant cells affect tumor aggressiveness independently. Additionally, these transcription factors also induce over- expression of HKII in the malignant cells and effect higher cellular proliferation and poor response to the anticancer treatment. Overexpression of HKII resulted in more cellular proliferation by up to 2 -fold and caused poorer response to anticancer treatment by 2- to 8-fold, compared with nontransfected cells (Fig. 4).

The antiapoptotic mechanisms of the mitochondriabound form HKII have been extensively investigated. HKII can directly bind to the mitochondrial outer membrane protein, known as VDAC (7). VDAC is the pore in the mitochondrial outer membrane through which all solutes including ATP are transported. Mitochondrial ATP is exported through the mitochondrial inner membrane by the ANT. Consequently, the HKII-VDAC-ANT binding interaction is crucial for energy supply as a form of ATP to the phosphorylation reaction and for enhancing tumor growth and cancer cell proliferation. HKII-VDAC-ANT complex also inhibits Bax or Bak binding to the mitochondria, and it prevents cytochrome $\mathrm{c}$ release, thereby inhibiting tumor cell apoptosis $(16,27)$.

These antiapoptotic effects of HKII are known to be mediated by the PI3K downstream molecule Akt (27). Akt mediates the signals of a variety of oncogenes or transcriptional factors for tumor progression (29). In this study, the active form of Akt (i.e., p-Akt) level was increased in SNU449-HKII cells, although PI3K or growth factor receptor in upstream level was not stimulated. Usually PI3K is activated by a large number of the plasma membrane growth factor receptors, particularly receptors with tyrosine kinase activity. PI3K is involved in the catalytic conversion of phosphatidylinositol-3,4-bisphosphate to phosphatidylinositol-3,4,5-trisphosphate (29). Activated PI3K recruits Akt and PDK1 (phosphoinositide-dependent kinase 1) to the plasma membrane. Akt is then activated by PDK1 and phosphorylates multiple proteins on serine and threonine residues (30).

PI3K/Akt signaling is important for the regulation of transcription, migration, angiogenesis, cell growth, proliferation, apoptosis, and glucose metabolism (31). In glucose metabolism, PI3K/Akt signaling is important for the translocation of cytosolic HKII to the outer membrane of the mitochondria for antiapoptotic activity as described earlier. 
Our results show that HKII dissociated from the mitochondria and liberated into the cytoplasm after treatment with a PI3K inhibitor LY294002 and support these mechanisms.

However, several reports have suggested that Akt could be activated in a PI3K-independent manner (32). Among them, AMPK - which plays a key role in the main regulation of cellular energy homeostasis-is known to be an important regulator of PI3K-independent Akt activation (33). Activated AMPK can inhibit mammalian target of rapamycin (mTOR), which is a downstream molecule of Akt, but inactivation of AMPK produces Akt activation alternatively $(34,35)$. Conditions that activate AMPK are glucose deprivation, hypoxia, ischemia, and heat shock, all of which are associated with depleted cellular ATP, elevated AMP levels, and an increased AMP-to-ATP ratio (34). Therefore, AMPK is activated under nutrient-poor conditions and inactive under nutrient-rich conditions (35). In our study, HKII-overexpressed SNU449 cells showed higher lactate production and ATP content and decreased p-AMPK level (Fig. 5; Supplemental Fig. 4). Based on these facts, Akt could be activated by an alternative PI3Kindependent AMPK signaling pathway in HKII overexpressed SNU449 cells, although growth factor receptor or PI3K stimulation was not induced.

The mTOR is an important central downstream molecule in both PI3K/Akt and AMPK pathways. This activates HIF1 (36) and activates HKII DNA promoter. It could be another mechanism for further increasing HKII levels in malignant cells (28), and vicious cycles ensue. In addition to the antiapoptotic role of overexpressed HKII by means of activated Akt, Akt itself has important functions as a critical regulator of cell survival and proliferation. Balsara et al. reported that Akt activation might have a role in the conversion from a benign to a malignant tumor (37). In addition, overexpression and mutation of Akt has been observed in various cancers (38). Furthermore, activated Akt accelerates tumor progression and promotes the malignant conversion of immortalized keratinocyte cell lines (39). These molecular mechanisms are summarized in Supplemental Figure 5.

\section{CONCLUSION}

Increased ${ }^{18} \mathrm{~F}$-FDG uptake in HCC reflects HKII overexpression; overexpressed HKIIs induce antiapoptotic activity with higher cellular proliferation and poor response to anticancer treatment through both the PI3K-dependent and the independent Akt signal pathways. Therefore, ${ }^{18} \mathrm{~F}-\mathrm{FDG}$ PET can be a surrogate marker of prognosis in HCC.

\section{ACKNOWLEDGMENTS}

This work was supported by the grant of the 2007 Korean National Cancer Control Program, Ministry of Health \& Welfare, Republic of Korea, and the Brain Korea 21 Project for Medical Science, Yonsei University, Seoul, Korea.

\section{REFERENCES}

1. Young H, Baum R, Cremerius U, et al. Measurement of clinical and sub-clinical tumour response using [F-18] fluorodeoxyglucose and positron emission tomography: review and 1999 EORTC recommendations. Eur J Cancer. 1999;35:17731782 .

2. Vansteenkiste JF, Stroobants SG, Dupont PJ, et al. Prognostic importance of the standardized uptake value on ${ }^{18} \mathrm{~F}$-fluoro-2-deoxy-glucose-positron emission tomography scan in non-small-cell lung cancer: an analysis of 125 cases. Leuven Lung Cancer Group. J Clin Oncol. 1999;17:3201-3206.

3. Lee JD, Yun M, Lee JM, et al. Analysis of gene expression profiles of hepatocellular carcinomas with regard to F-18-FDG uptake pattern on positron emission tomography. Eur J Nucl Med Mol Imaging. 2004;31:1621-1630.

4. Higashi T, Saga T, Nakamoto $Y$, et al. Relationship between retention index in dual-phase ${ }^{18} \mathrm{~F}-\mathrm{FDG}$ PET, and hexokinase-II and glucose transporter-1 expression in pancreatic cancer. $J$ Nucl Med. 2002;43:173-180.

5. Lee JD, Yang WI, Park YN, et al. Different glucose uptake and glycolytic mechanisms between hepatocellular carcinoma and intrahepatic mass-forming cholangiocarcinoma with increased ${ }^{18}$ F-FDG uptake. J Nucl Med. 2005;46: 1753-1759.

6. Warburg O. On the origin of cancer cells. Science. 1956;123:309-314.

7. Bustamante E, Pedersen PL. High aerobic glycolysis of rat hepatoma cells in culture: role of mitochondrial hexokinase. Proc Natl Acad Sci USA. 1977; 74:3735-3739.

8. Wallace DC. A mitochondrial paradigm of metabolic and degenerative diseases, aging, and cancer: a dawn for evolutionary medicine. Annu Rev Genet. 2005;39: 359-407.

9. Bustamante E, Morris HP, Pedersen PL. Energy metabolism of tumor cells: requirement for a form of hexokinase with a propensity for mitochondrial binding. J Biol Chem. 1981;256:8699-8704.

10. Arora KK, Pedersen PL. Functional significance of mitochondrial bound hexokinase in tumor cell metabolism: evidence for preferential phosphorylation of glucose by intramitochondrially generated ATP. J Biol Chem. 1988;263: 17422-17428.

11. Rempel A, Mathupala SP, Griffin CA, Hawkins AL, Pedersen PL. Glucose catabolism in cancer cells: amplification of the gene encoding type II hexokinase. Cancer Res. 1996;56:2468-2471.

12. Golshani-Hebroni SG, Bessman SP. Hexokinase binding to mitochondria: a basis for proliferative energy metabolism. J Bioenerg Biomembr. 1997;29:331-338.

13. Pastorino JG, Hoek JB. Hexokinase II: the integration of energy metabolism and control of apoptosis. Curr Med Chem. 2003;10:1535-1551.

14. Wilson JE. Isozymes of mammalian hexokinase: structure, subcellular localization and metabolic function. J Exp Biol. 2003;206:2049-2057.

15. Pelicano H, Martin DS, Xu RH, Huang P. Glycolysis inhibition for anticancer treatment. Oncogene. 2006;25:4633-4646.

16. Pastorino JG, Shulga N, Hoek JB. Mitochondrial binding of hexokinase II inhibits Bax-induced cytochrome c release and apoptosis. J Biol Chem. 2002;277:7610-7618.

17. Roh MS, Jeong JS, Kim YH, Kim MC, Hong SH. Diagnostic utility of Glut 1 in the differential diagnosis of liver carcinomas. Hepatogastroenterology. 2004;51: 1315-1318.

18. Zimmerman RL, Fogt F, Burke M, Murakata LA. Assessment of Glut-1 expression in cholangiocarcinoma, benign biliary lesion and hepatocellular carcinoma. Oncol Rep. 2002;9:689-692.

19. Chen YT, Stockert E, Chen Y, et al. Identification of the $M A G E-1$ gene product by monoclonal and polyclonal antibodies. Proc Natl Acad Sci USA. 1994;91: 1004-1008.

20. Robey RB, Hay N. Mitochondrial hexokinases: novel mediators of the antiapoptotic effects of growth factors and Akt. Oncogene. 2006;25:4683-4696.

21. Rigo P, Paulus P, Kaschten BJ, et al. Oncological applications of positron emission tomography with fluorine-18 fluorodeoxyglucose. Eur J Nucl Med. 1996;23:1641-1674.

22. Schroder O, Trojan J, Zeuzem S, Baum RP. Limited value of fluorine-18fluorodeoxyglucose PET for the differential diagnosis of focal liver lesions in patients with chronic hepatitis C virus infection. Nuklearmedizin. 1998;37:279285.

23. Whitesell RR, Ardehali H, Beechem JM, et al. Compartmentalization of transport and phosphorylation of glucose in a hepatoma cell line. Biochem J. 2005;386:245-253.

24. Czernin J, Phelps ME. Positron emission tomography scanning: current and future applications. Annu Rev Med. 2002;53:89-112.

25. Aloj L, Caraco C, Jagoda E, Eckelman WC, Neumann RD. Glut-1 and hexokinase expression: relationship with 2-fluoro-2-deoxy-D-glucose uptake in A431 and T47D cells in culture. Cancer Res. 1999;59:4709-4714. 
26. Pedersen PL, Mathupala S, Rempel A, Geschwind JF, Ko YH. Mitochondrial bound type II hexokinase: a key player in the growth and survival of many cancers and an ideal prospect for therapeutic intervention. Biochim Biophys Acta. 2002;1555:14-20.

27. Gottlob K, Majewski N, Kennedy S, Kandel E, Robey RB, Hay N. Inhibition of early apoptotic events by Akt/PKB is dependent on the first committed step of glycolysis and mitochondrial hexokinase. Genes Dev. 2001;15:1406-1418.

28. Gillies RJ, Robey I, Gatenby RA. Causes and consequences of increased glucose metabolism of cancers. J Nucl Med. 2008;49(suppl):24S-42S.

29. Song G, Ouyang G, Bao S. The activation of Akt/PKB signaling pathway and cell survival. J Cell Mol Med. 2005;9:59-71.

30. Paez J, Sellers WR. PI3K/PTEN/AKT pathway: a critical mediator of oncogenic signaling. Cancer Treat Res. 2003;115:145-167.

31. Hennessy BT, Smith DL, Ram PT, Lu Y, Mills GB. Exploiting the PI3K/AKT pathway for cancer drug discovery. Nat Rev Drug Discov. 2005;4:988-1004.

32. Filippa N, Sable CL, Filloux C, Hemmings B, Van Obberghen E. Mechanism of protein kinase B activation by cyclic AMP-dependent protein kinase. Mol Cell Biol. 1999;19:4989-5000.
33. Hardie DG. The AMP-activated protein kinase pathway: new players upstream and downstream. J Cell Sci. 2004;117:5479-5487.

34. Kuhajda FP. AMP-activated protein kinase and human cancer: cancer metabolism revisited. Int J Obes (Lond). 2008;32(suppl):S36-S41.

35. Toker A. mTOR and Akt signaling in cancer: SGK cycles in. Mol Cell. 2008;31:6-8.

36. Majumder PK, Febbo PG, Bikoff R, et al. mTOR inhibition reverses Aktdependent prostate intraepithelial neoplasia through regulation of apoptotic and HIF-1-dependent pathways. Nat Med. 2004;10:594-601.

37. Balsara BR, Pei J, Mitsuuchi Y, et al. Frequent activation of AKT in non-small cell lung carcinomas and preneoplastic bronchial lesions. Carcinogenesis. 2004; 25:2053-2059.

38. Itoh N, Semba S, Ito M, Takeda H, Kawata S, Yamakawa M. Phosphorylation of $\mathrm{Akt} / \mathrm{PKB}$ is required for suppression of cancer cell apoptosis and tumor progression in human colorectal carcinoma. Cancer. 2002;94:31273134 .

39. Segrelles C, Ruiz S, Perez P, et al. Functional roles of Akt signaling in mouse skin tumorigenesis. Oncogene. 2002;21:53-64. 